\title{
Potential control of forest diseases by solutions of chitosan oligomers, propolis and nanosilver
}

Iosody Silva-Castro ${ }^{1 *}$, Jorge Martín-García ${ }^{2,3}$, Julio Javier Diez ${ }^{3,4}$, Juan Asdrúbal FloresPacheco $^{3,4}$, Jesús Martín-Gil $^{1}$ and Pablo Martín-Ramos ${ }^{5}$

${ }^{1}$ Department of Agricultural and Forestry Engineering, ETSIIAA, University of Valladolid, Avenida de Madrid 44, 34004 Palencia, Spain.

${ }^{2}$ Department of Biology, CESAM (Centre for Environmental and Marine Studies), University of Aveiro, Campus Universitario de Santiago, 3810-193 Aveiro, Portugal.

${ }^{3}$ Sustainable Forest Management Research Institute, University of Valladolid - INIA, Avenida de Madrid 57, 34004 Palencia, Spain.

${ }^{4}$ Department of Plant Production and Forestry Resources, ETSIIAA, University of Valladolid, Avenida de Madrid 57, 34004 Palencia, Spain.

${ }^{5}$ Department of Agricultural and Environmental Sciences, EPS, Instituto de Investigación en Ciencias Ambientales de Aragón (IUCA), Universidad de Zaragoza, Carretera de Cuarte s/n, 22071 Huesca, Spain.

* Corresponding author at: Agriculture and Forestry Engineering Department, ETSIIAA, University of Valladolid, Avenida de Madrid 44, 34004 Palencia, Spain. Email: iosody.silva@alumnos.uva.es

\section{Abstract}

There is a growing necessity to replace chemical agents with ecofriendly materials, arising from their impact on the environment and/or human health, which calls for the design of new broadspectrum fungicides. In this work, chitosan oligomers (COs), propolis (Ps) and silver nanoparticles (AgNPs) mixtures in solution were assessed to control the growth of different phytopathogenic fungi and oomycetes in vitro. Binary solutions of COs-Ps and COs-AgNPs evinced the highest antifungal effect against Fusarium circinatum and Diplodia pinea fungi, respectively, with a $c a .80 \%$ reduction in their mycelial growth. The COs solution by itself also proved to be greatly effective against Gremmeniella abietina, Cryphonectria parasitica and Heterobasidion annosum fungi, causing a reduction of $78 \%, 86 \%$ and $93 \%$ in their growth rate, respectively. Likewise, COs also attained a $100 \%$ growth inhibition on the oomycete Phytophthora cambivora. On the other hand, Ps inhibited totally the growth of Phytophthora $\times$ alni and Phytophthora plurivora. The application of AgNPs reduced the mycelial growth of F. circinatum and D. pinea. However, the AgNPs in some binary and ternary mixtures had a counter-productive effect on the anti-fungal/oomycete activity. In spite of the fact that the anti-fungal/oomycete activity of the different treatments showed a dependence on the particular type of microorganism, these solutions based on natural compounds can be deemed as a promising tool for control of tree diseases. 
41 Keywords: anti-fungal; anti-oomycetes; forest pathogens; natural compounds.

\section{Introduction}

Phytopathogenic microorganisms are responsible for major economic losses and ecological impacts, affecting from seedling nurseries to mature trees in plantations, seed orchards, landscape plantings, or native forests (Hirooka and Ishii 2013; Gordon et al. 2015). All over the world, several species of conifers are affected by common ascomycete fungi, such as Fusarium circinatum Nirenberg \& O'Donnell, responsible for pitch canker disease (Wingfield et al. 2008); Diplodia pinea (Desmaz.) J. Kickx fil. (= Sphaeropsis sapinea (Fr.) Dyko \& Sutton), which causes Diplodia tip blight and stem canker disease (Gibson 1979; Adamson et al. 2015); and Gremmeniella abietina (Lagerberg) Morelet (anamorph: Brunchorstia pinea (P. Karsten) Höhnel) that produces shoots dieback and cankers on stems and trunks (Kaitera and Jalkanen 1992; Romeralo et al. 2015), causing the death of conifers including spruce, fir, larch, pine and juniper. In the same way, another of the most important pathogens in coniferous forests is Heterobasidion annosum (Fr.) Bref. (= Fomes annosus (Fr.) Cooke) basidiomycete, which causes root and butt rot (Asiegbu et al. 2005; Garbelotto and Gonthier 2013).

Other main forest pathogens include Cryphonectria parasitica, one of the most undesirable introduced plant pathogens, which causes chestnut blight on species in the genus Castanea (Heiniger and Rigling 1994; González-Varela et al. 2011); and oomycetes species such as Phytophthora. These latter comprise P. cambivora (Petri) Buisman, also a common pathogen of Castanea, Fagus and other hardwoods (Jung et al. 2005); P. × alni (Brasier \& S.A. Kirk) Husson, Ioos \& Marçais, nothosp. nov., which cause alder decline by dieback, small sparse and yellowish leaves, excessive fructification, and tarry and rusty exudates (Husson et al. 2015); and P. plurivora T. Jung and T.I. Burgess, which causes aerial canker and collar rot in several species, including beech, oaks and alders (Jung and Burgess 2009; Haque et al. 2014; Haque et al. 2015).

To date, control of plant diseases has typically been performed by application of high toxic chemicals, whose excessive use has occasioned undesired impacts on the environment and on human health (Hirooka and Ishii 2013). Moreover, regulations are increasingly limiting the utilization of

69 high toxic chemicals and promoting the use of integrated pest management and non-chemical alternatives to pesticides (Directive 2009/128/EC).

71 Chitosan is a natural polymer composed of randomly distributed $\beta$-(1-4) D-glucosamine and N72 acetyl-D-glucosamine units. It can be found in the form of chitin in the shells of crustaceans and in 
the cell walls of fungi (Jayakumar et al. 2011). This cationic biopolymer is characterized by being biocompatible, biodegradable, non-toxic and features antimicrobial, antiviral and antifungal properties (Ngo et al. 2015). Indeed, all fungi are expected to be vulnerable to chitosan, except those containing chitosan as a major wall compound (i.e. zygomycetes) (Leuba \& Stössel, 1986, cited in Laflamme et al. (2000)).

Another natural compound that has been widely used for its antiseptic properties, mainly in traditional medicine, but also in plant protection (Özcan et al. 2004), is propolis. It is a resinous material collected by bees from different parts of plants, buds and exudates, which -once mixed with their own enzymes- is used as a void sealant or as a sanitization agent in the hive (Marcucci 1995). Propolis is rich in flavonoids, polyphenols, steroids, aldehydes, amino acids and quinones, which account for its strong antimicrobial power (Farooqui 2012; Mărghitaş et al. 2013).

Regarding silver nanoparticles, they have gained attention in the past decade as a very promising bactericidal and antifungal agent, with a much higher activity than silver ions (Kashyap et al. 2012). Silver nanoparticles have the ability to destroy the cellular walls and interfere with bacterial DNA replication and protein production processes (Wei et al.2009).

Natural alternatives based on chitosan products have been widely studied against plant diseases, meanly in the crop protection, such as rice (Boonlertnirun et al. 2008), soybean (Zeng et al. 2012) and potatoes (Kurzawińska and Mazur 2006), to name a few. So that, the development of application strategies such as seeds coating, foliar treatment and soil amendment is very broad (El Hadrami et al. 2010). Nonetheless, against forest diseases there are very few reports regard of chitosan uses (e.g. Reglinski et al. 2004; Fitza et al. 2013).

In this work, the anti-fungal/oomycete activity of chitosan oligomers (COs), propolis (Ps) and silver nanoparticles (AgNPs) and their binary and ternary combinations in solution has been assessed against eight forest pathogens through an in vitro study. The information on their effectiveness against each of the pathogens could pave the way for the development of novel natural compound-based antifungals, useful in an integrated management approach.

\section{Materials and methods}

\subsection{Fungal material and reagents}

To assay in vitro the effects of the different mixtures, eight species -five fungi and three oomycetes- were chosen. All these pathogens were isolated in natural areas in the North-West of 

medium in order to preserve the standard mycelial growth before the treatments.

106

Table 1. Assayed fungi and oomycetes, isolated in previous studies.

\begin{tabular}{|c|c|c|c|c|c|}
\hline Species & Isolate & Host tree & Origin & Isolation year & References \\
\hline \multicolumn{6}{|l|}{ Fungi } \\
\hline $\begin{array}{l}\text { Fusarium } \\
\text { circinatum }\end{array}$ & FcCal & $\begin{array}{l}\text { Pinus } \\
\text { radiata }\end{array}$ & Cantabria & 2009 & (Martínez-Álvarez et al. 2012) \\
\hline Diplodia pinea & HP154 & $\begin{array}{l}\text { Pinus } \\
\text { radiata }\end{array}$ & Cantabria & 2009 & (Martínez-Álvarez et al. 2016) \\
\hline $\begin{array}{l}\text { Gremmeniella } \\
\text { abietina }\end{array}$ & VAI-13 & $\begin{array}{l}\text { Pinus } \\
\text { halepensis }\end{array}$ & Valladolid & 2003 & (Botella et al. 2010) \\
\hline $\begin{array}{l}\text { Cryphonectria } \\
\text { parasitica }\end{array}$ & EU1 & $\begin{array}{l}\text { Castanea } \\
\text { sativa }\end{array}$ & Zamora & 2005 & 2012) \\
\hline $\begin{array}{l}\text { Heterobasidion } \\
\text { annosum }\end{array}$ & $\begin{array}{l}\text { A14009- } \\
\text { AFZAPR001 }\end{array}$ & $\begin{array}{l}\text { Pinus } \\
\text { pinaster }\end{array}$ & Zamora & 2014 & \\
\hline \multicolumn{6}{|l|}{ Oomycetes } \\
\hline $\begin{array}{l}\text { Phytophthora } \\
\text { cambivora }\end{array}$ & $\begin{array}{l}\text { PH14012- } \\
\text { LR2-2 }\end{array}$ & Quercus ile & Segovia & & \\
\hline $\begin{array}{l}\text { Phytophthora } \\
\times \text { alni }\end{array}$ & PA02 & $\begin{array}{l}\text { Alnus } \\
\text { glutinosa }\end{array}$ & Zamora & & (Zamora-Ballesteros et al. \\
\hline $\begin{array}{l}\text { Phytophthora } \\
\text { plurivora }\end{array}$ & SORLDD4 & $\begin{array}{l}\text { Alnus } \\
\text { glutinosa }\end{array}$ & Soria & & $\begin{array}{l}\text { (Haque et al. 2014; Zamora- } \\
\text { Ballesteros et al. 2016) }\end{array}$ \\
\hline
\end{tabular}

Unless otherwise stated, all chemicals and reagents were supplied by Sigma-Aldrich Química S.A. (Tres Cantos, Madrid) and were used without further purification. Chitosan with medium molar mass was purchased from Hangzhou Simit Chemical Technology Co. (Hangzhou, China). Propolis with a content of polyphenols and flavonoids of $c a .10 \%$ (w/v) came from Burgos (Spain).

\subsection{Synthesis of chitosan-based mixtures in solution}

The synthesis of the solutions based on COs with Ps and AgNPs was conducted according to the procedure described by Matei et al. (2015), with some modifications. COs aqueous solutions were prepared from medium molecular weight commercial chitosan (140000-300000 g/mol) in AcOH 2\% at $\mathrm{pH} 4-6$, after neutralization with $\mathrm{KOH}$. However, when the final $\mathrm{pH}$ of the substrate was close to 6, there was no influence on the growth of the pathogen (Jönsson-Belyazio and Rosengren 2006). Then, $0.3 \mathrm{M} \mathrm{H}_{2} \mathrm{O}_{2}$ was added to obtain $2000 \mathrm{~g} / \mathrm{mol}$ oligomers. Ps extraction was carried out by grinding raw propolis to fine powder and by maceration in a hydroalcoholic solution 7:3 (v/v), which was subsequently percolated $(1 \mathrm{~L} / \mathrm{min})$ and filtrated with a stainless steel 220 mesh to remove any residues. AgNPs were prepared with the procedure described by Venkatesham et al. (2012), where the nanoparticles from an aqueous solution of $\mathrm{AgNO}_{3}(50 \mathrm{mM})$ were obtained with chitosan acting as both reducing and stabilizing agent without using any toxic chemicals. The reaction was carried 
127 out in an autoclave at $120^{\circ} \mathrm{C}$ for $15 \mathrm{~min}$ to obtain a clear yellow color indicating the formation of 128 silver nanoparticles.

129 COs-Ps, COs-AgNPs, Ps-AgNPs binary and COs-Ps-AgNPs ternary solutions were prepared by 130 mixing - under vigorous stirring- the necessary volumes of each solution in order to obtain a 131 concentration of $10 \mathrm{mg} / \mathrm{mL}$ of COs, $1 \mathrm{mg} / \mathrm{mL}$ of Ps and $10 \mu \mathrm{g} / \mathrm{mL}$ of AgNPs in every solution. The 132 AgNPs content was kept to a minimum to preserve the stability of the nanoparticles.

133 In order to characterize the mixtures and identify the interaction of the chemical functional groups, 134 the samples in solution were freeze-dried (lyophilized) for 24 hours and their infrared spectra in the $135400-4000 \mathrm{~cm}^{-1}$ spectral range was measured using a Thermo Scientific (Waltham, MA, USA) Nicolet 136 iS50 FT-IR Spectrometer, equipped with an in-built diamond attenuated total reflection (ATR) 137 system.

\subsection{In vitro experiments}

140 To assay the anti-fungal/oomycete activity, a typical in vitro mycelial growth inhibition test was 141 performed. Indeed, the experimental design consisted of a factorial scheme with three factors: (1) 142 COs (presence/absence), (2) Ps (presence/absence) and (3) AgNPs (presence/absence). So, the anti143 fungal/oomycete activity of the three compounds separately and their binary and ternary 144 combinations was analyzed for each pathogen (Figure 1). Each solution was uniformly incorporated 145 at a ratio of $1: 10(\mathrm{v} / \mathrm{v})$ into PDA after its sterilization for $20 \mathrm{~min}$ at $121^{\circ} \mathrm{C}$, as described by Wang et 146 al. (2014), obtaining a final concentration of $1 \mathrm{mg} / \mathrm{mL}$ of COs, $0.1 \mathrm{mg} / \mathrm{mL}$ of $\mathrm{P}$ and $1 \mu \mathrm{g} / \mathrm{mL}$ of 147 AgNPs in every treatment. These concentrations correspond to the minimum inhibitory 148 concentrations used in other similar studies (Yoksan and Chirachanchai 2010; Torlak and Sert 2013; 149 Olicón-Hernández et al. 2015). $20 \mathrm{~mL}$ of the mixtures were spread in Petri dishes (9 $\mathrm{cm}$ in diameter) 150 setting four replicates for each treatment.

151 Once the culture medium had solidified, an inoculum of every pathogen (a $5 \times 5 \mathrm{~mm}^{2}$ plug cut from 152 the margins) was placed at the center of the Petri dish. Then, Petri dishes were sealed and incubated 153 at $25^{\circ} \mathrm{C}$ in the dark. The mycelial growth $(g)$ was measured on a daily basis until the day in which 154 the dishes of the control treatment were fully covered with mycelium $(n)$.

155 The radial growth rate was calculated according to the following equation: 


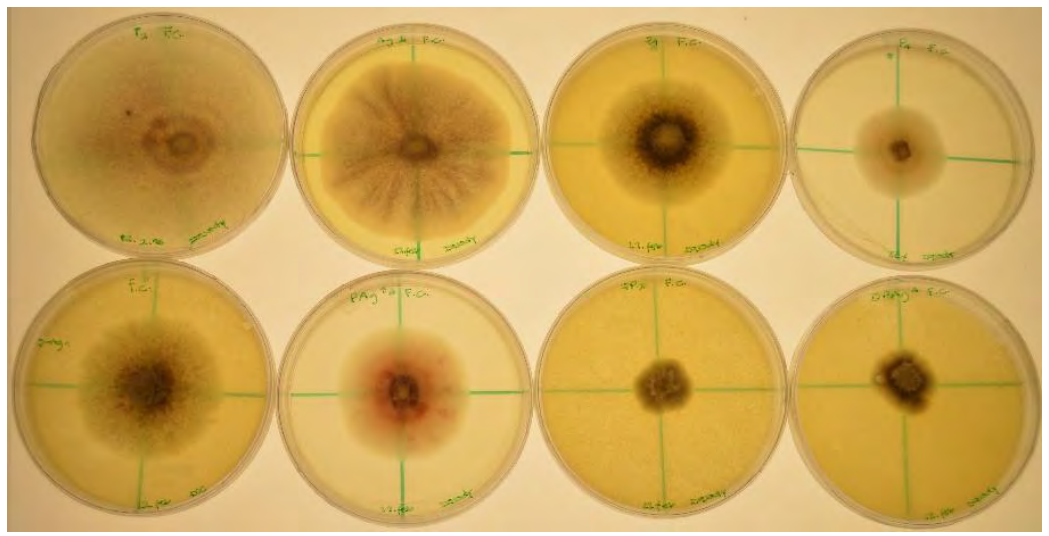

Figure 1. In vitro growth inhibition test for Fusarium circinatum (day 7). Control and treatments with AgNPs, COs, Ps, COs-AgNPs, Ps-AgPNs, COs-Ps, COs-Ps-AgNPs (left-to-right, top-to-bottom).

\subsection{Statistical analyses}

Analyses of variance (ANOVAs) and multiple comparison procedures were performed to test the effect of three different anti-fungal/oomycete agents (chitosan, propolis and nanosilver) and their combinations on the mycelia growth of the eight forest pathogens. As the raw data violated two ANOVA assumptions (normality and homogeneity of variances), robust methods were applied (García Pérez 2011). In particular, three-way fixed factor ANOVAs were performed under nonnormality and inequality of variances, using the generalized Welch procedure, a 0.2-trimmed mean transformation and alpha value of 0.05 . ANOVAs were carried out using the "Wilcox' Robust Statistics (WRS2)" package, in particular the functions "t3way" and "lincon" (see Wilcox (2016)), implemented in the R software environment (R Development Core Team 2016).

\section{Results}

\subsection{Aqueous solutions characterization}

Insight into the interaction of COs with the functional groups (phenolic and acids) from Ps and into the chelation of AgNPs in the binary and ternary aqueous solutions was gained by attenuated total reflectance Fourier-transform infrared (ATR-FTIR) spectroscopy. The vibrational spectra of the COs, COs-Ps binary and COs-Ps-AgNPs ternary mixtures were depicted in Figure 2. 


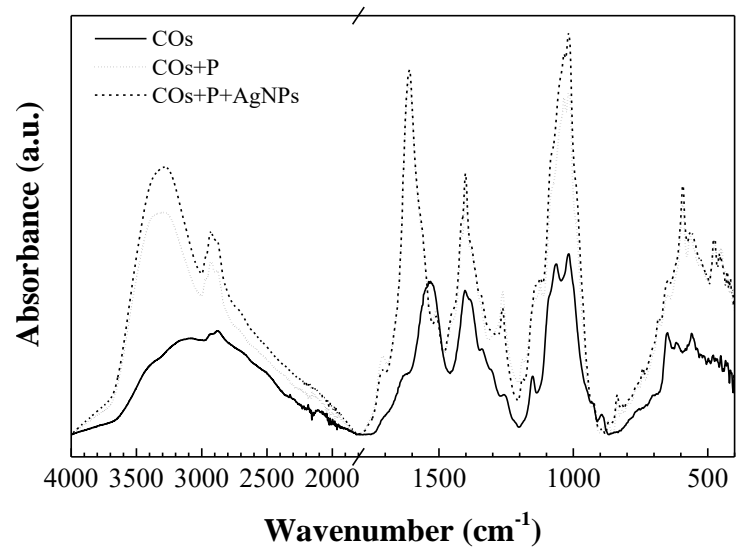

Figure 2. ATR-FTIR spectra of chitosan oligomers (COs), binary solution of chitosan oligomers and propolis (COs-Ps) and ternary solution of chitosan oligomers, propolis and silver nanopartícles (COs-Ps-AgNPs). A break has been inserted in the $x$-axis at $1800 \mathrm{~cm}^{-1}$ to allow a clearer representation of the fingerprint region.

The COs spectrum (solid line in Figure 2) showed the characteristic absorption peaks of chitosan at $3256 \mathrm{~cm}^{-1}$ (stretching vibration of the $\mathrm{O}-\mathrm{H}$ and $\mathrm{N}-\mathrm{H}$ bonds); at 1633 and $1550 \mathrm{~cm}^{-1}$ (amide $\mathrm{I}(\mathrm{C}=\mathrm{O}$ stretching) and to $\mathrm{N}-\mathrm{H}$ (amine) vibration overlapped to amide II (N-H vibration), respectively); at $1152 \mathrm{~cm}^{-1}$ ( $\mathrm{C}-\mathrm{O}$ in oxygen bridges resulting from deacetylation of chitosan); and at 1065 and 1018 $\mathrm{cm}^{-1}$ (C-O-C and $\mathrm{C}-\mathrm{O}$ vibrations).

The spectrum of the binary mixture of COs-Ps (dotted line in Figure 2) sensitized the interaction between the two components by significant changes ys. the COs spectrum, caused by the bonded Ps components (mainly flavonoids and lipids). An increase in the intensity of the bands at $1165 \mathrm{~cm}^{-1}(\mathrm{C}-$ $\mathrm{O}$ and $\mathrm{C}-\mathrm{OH}$ vibration), $1434 \mathrm{~cm}^{-1}\left(\mathrm{C}-\mathrm{H}\right.$ vibration), 1508 and $1610 \mathrm{~cm}^{-1}$ (aromatic ring deformations), and $1681 \mathrm{~cm}^{-1}(\mathrm{C}=\mathrm{O}$ stretching) took place. Another important difference between the COs-Ps and COs spectra was a shift of the band associated to $v\left(\mathrm{C}_{\Phi^{-}} \mathrm{O}\right)$ from $1257 \mathrm{~cm}^{-1}$ to 1263 $\mathrm{cm}^{-1}$, which occurs when hydrogen bonding between COs and phenolic groups from Ps components takes place.

The lyophilizate of the ternary mixture COs-Ps-AgNPs (dashed line in Figure 2) showed a very similar pattern to the infrared spectrum of the COs-Ps binary mixture, albeit with a decrease in intensity for the bands at 1721,1271 and $1130 \mathrm{~cm}^{-1}$. This change, unaccompanied by a shift in the bands, suggests weak bonding of $\mathrm{NH}_{2}$-AgNPs.

\subsection{Anti-fungal activity}

All individual agents and some mixtures demonstrated the ability to reduce the mycelial growth of fungi (Figure 3), in particular those with COs, however, their antifungal activity was dependent on the particular type of pathogen assayed. With regard to $F$. circinatum fungi (Figure $3 a$ ), an interaction 
amongst the three agents was observed in the Post-hoc analysis $(F=354.6, p<0.001)$. Nevertheless, the binary mixture of COs-Ps showed the best antifungal effect, where the radial growth rate (1.4 $\mathrm{mm} \cdot$ day $\left.^{-1}\right)$ was 5.6 times lower than of the control treatment $\left(8.0 \mathrm{~mm} \cdot\right.$ day $\left.^{-1}\right)$, corresponding to $82 \%$ of inhibition. In this case, the addition of AgNPs did not increase the effectiveness of the COs-Ps binary solution, whereas it reduced the effect of Ps and COs as individual compounds, which presented a high capacity to inhibit the mycelial growth, with a $68 \%$ and $53 \%$ of inhibition, respectively. However, AgNPs by itself, although in a lesser extent, also inhibited the mycelial growth regarding the control (27\% of inhibitions).

The treatments against $D$. pinea (Figure $3 b$ ) also showed an interaction amongst the three agents in the Post-hoc analysis $(F=7.4, p=0.02)$. The binary mixture COs-AgNPs showed the best antifungal effect, with a radial growth rate of $0.9 \mathrm{~mm} \cdot \mathrm{day}^{-1}$, over 4.3 times lower than the control treatment (3.9 $\mathrm{mm} \cdot$ day $^{-1}$ ), that is equivalent to $77 \%$ of inhibition. No significant differences were found considering the addition of Ps in the ternary mixture (COs-Ps-AgNPs). Nonetheless, the binary mixture of COsPs showed a $69 \%$ of inhibition. The separate application of COs, Ps and AgNPs also evinced some antifungal activity, with lower radial growth rates of 1.7, 2.4 and $3.2 \mathrm{~mm} \cdot$ day $^{-1}$, i.e., 55,37 and $18 \%$ of inhibition, respectively.

With regard to G. abietina (Figure 3c), there was an interaction between COs and $\operatorname{AgNPs}(F=6.6$, $p=0.03$ ). The best antifungal effect was associated to COs, which caused a $78 \%$ reduction of the growth rate. On the contrary, the addition of AgNPs to COs not only did not improve the antifungal activity, but had a counter-productive effect. No significant differences were found with AgNPs solution in comparison to the control.

In relation to C. parasitica ascomycete (Figure $3 d$ ), the results showed an interaction between COs and Ps $(F=371, p=0.001)$, and the effectiveness of COs both with and without Ps was around 93\%. This study seems to point out that there is no advantage in adding Ps to the COs, in spite of that the inhibition percentage of the individual Ps solution was also high (2.35 mm day ${ }^{-1}, 64 \%$ inhibition).

The treatments on $H$. annosum basidiomycete (Figure 3e) showed a high antifungal activity of individual COs solution ( $86 \%$ of inhibition), without any interactions amongst the three elements, so it may be inferred that the use of Ps and AgNPs, by themselves, or in addition to COs did not significantly increase the inhibitory effect. 

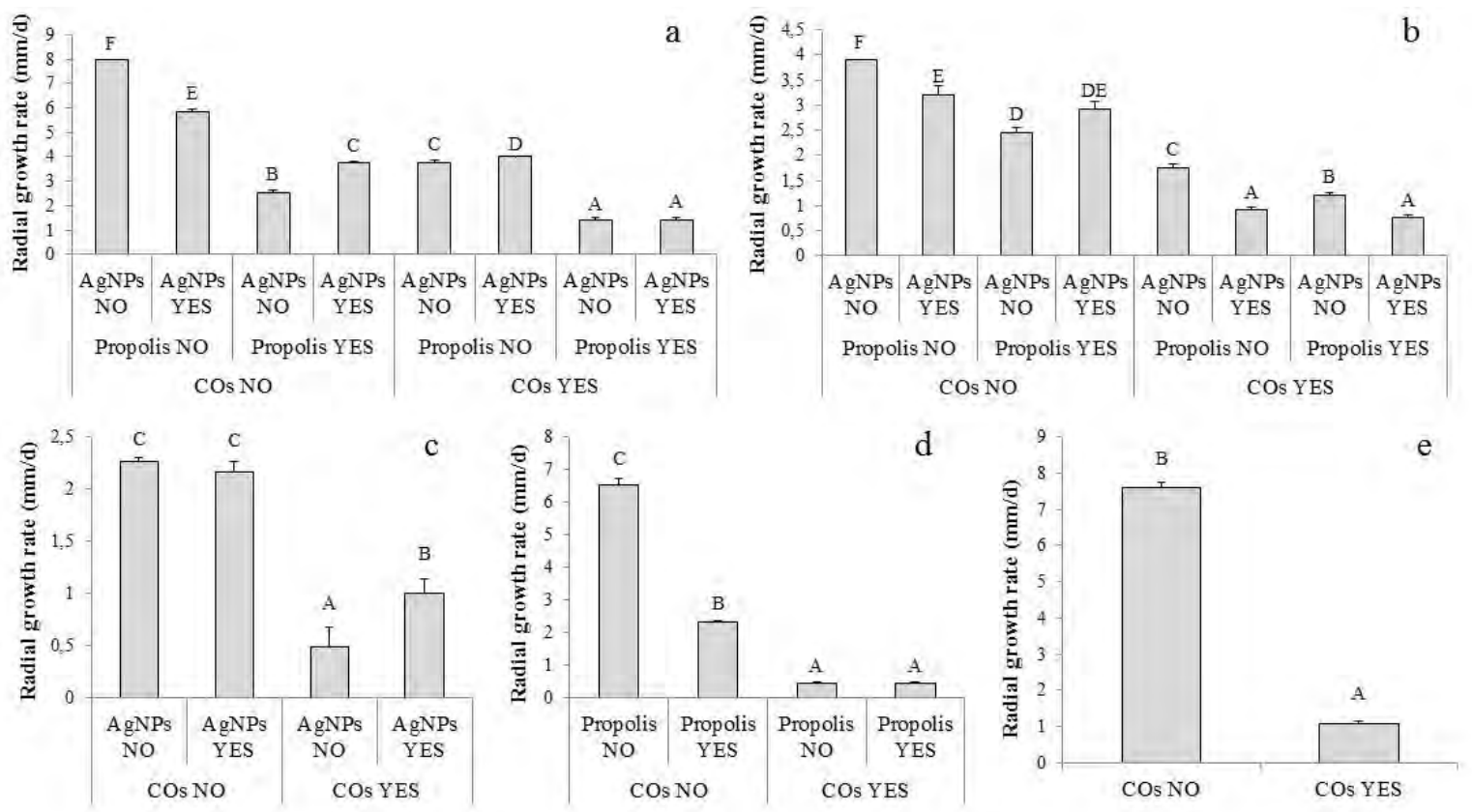

Figure 3. Radial growth rate and interaction among treatments based on chitosan oligomers (COs), Propolis and silver nanoparticles (AgNPs) against (a) F. circinatum; (b) D. pinea; (c) G. abietina; (d) C. parasitica; and (e) H. annosum fungi. Different letters above bars indicate significantly different means (generalized Welch procedure 0.2 trimmed means, $a=0.05$ ). Error bars show the standard deviation. Note: Only significant interactions from the Post hoc analyses are shown.

\subsection{Anti-oomycete activity}

As regards the assays conducted with oomycetes (Figure 4), a remarkable inhibitory activity was attained for COs and Ps. Treatments against $P$. cambivora (Figure $4 a$ ) evidenced an interaction among the three agents $(F=64.1, p=0.001)$, but all treatments with COs (individual, binary and ternary mixtures) presented $100 \%$ of growth inhibition. The treatment with the individual Ps solution also

253 showed growth inhibition (43\%), but AgNPs and Ps-AgNPs treatments did not exhibit any significant differences $v s$. the control.

On the other hand, an interaction between COs and Ps was found in treatments against $P . \times$ alni and $P$. plurivora $(F=23, p=0.002$ and $F=722.8, p=0.001$, respectively). While the application of COs and Ps (individual or mixed) resulted in a similar growth inhibition for $P$. $\times$ alni, the addition of Ps played a leading role in the growth inhibition for P. plurivora (Figure $4 b$ and Figure $4 c$ ). 

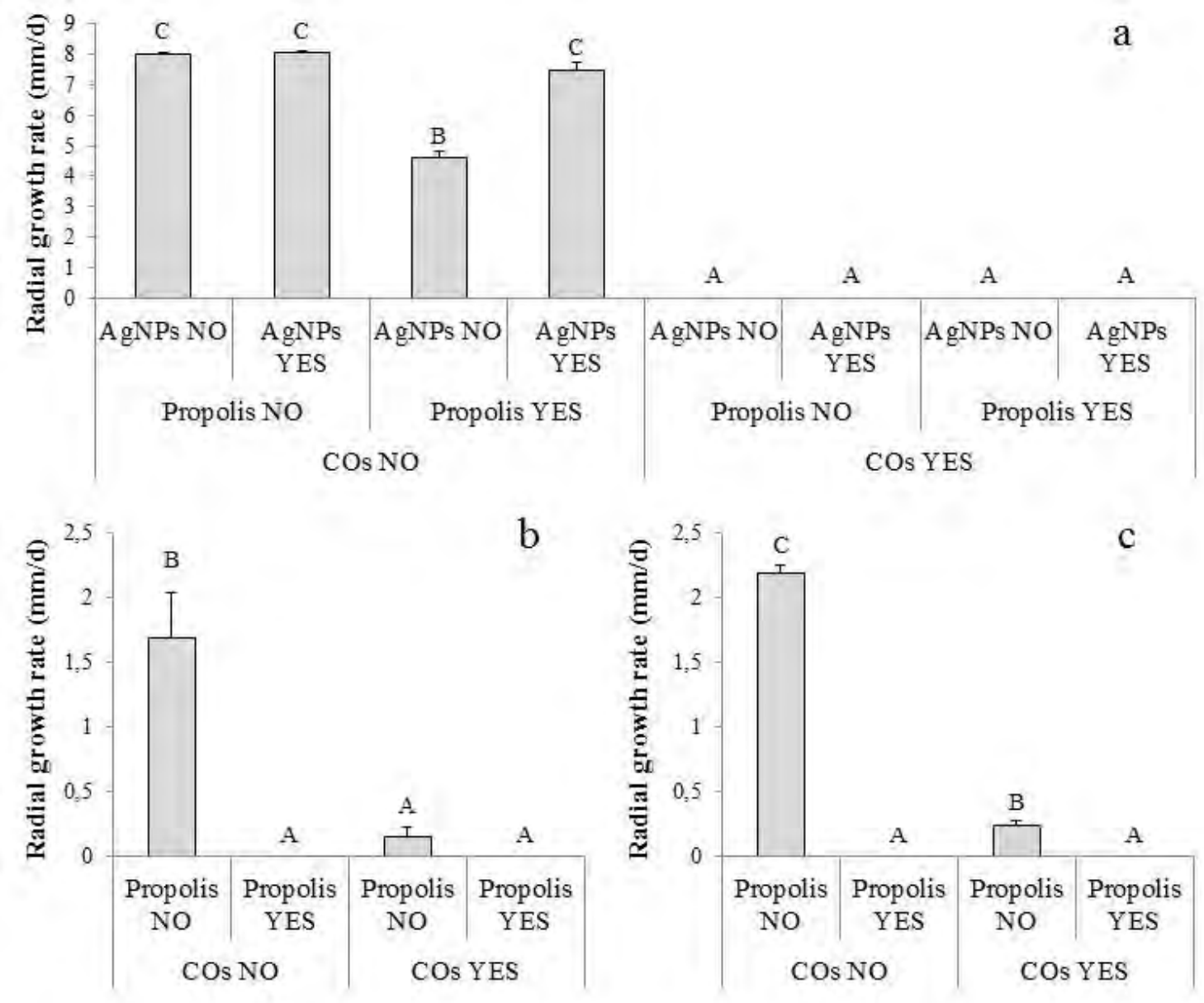

Figure 4. Radial growth rate and interaction among treatments based on chitosan oligomers (COs), Propolis and silver nanoparticles (AgNPs) against (a) P. cambivora; (b) P. ×alni; and (c) P. plurivora oomycetes. Different letters above bars indicate significantly different means (generalized Welch procedure 0.2 trimmed means, $\mathrm{a}=0.05)$. Error bars show the standard deviation. Note: Only significant interactions from the Post hoc analyses are shown.

\section{Discussion}

The present study has demonstrated that the three compounds (COs, Ps and AgNPs) have an antifungal effect on different forest pathogens. COs by itself showed an inhibitory effect on the mycelial growth of all pathogens tested. Although the antifungal activity of chitosan polymer has been already reported by other authors both in in vitro and in vivo experiments, for example, chitosan applications to increase the resistance of pine seedlings to $F$. circinatum and D. pinea (Reglinski et al. 2004; Fitza et al. 2013), this study confirms the importance of the use of low molecular weight chitosan such as COs. It is worth noting that when chitosan with higher molecular weight than that used in this study (e.g., 50,000 Da instead 2,000 Da) are applied, a lower antifungal activity is attained, with $35 \%$ of reduction of mycelial growth of $D$. pinea in the first day as reported by Singh 
et al. (2008). This is consistent with the results reported by Avelelas et al. (2014), Qiu et al. (2014) and Cobos et al. (2015), who demonstrated that chitosan antifungal activity increased in inverse proportion to its molecular weight. Consequently, COs of molecular weight under 2,000 Da, might be a preferable option as compared to commercial 'low molecular weight' chitosan (i.e., 50,000 to 190,000 Da, CAS Number 9012-76-4) in terms of its activity against D. pinea. On the other hand, in an in vitro study by Ziani et al. (2009), the use of chitosan solutions proved to be more effective against Aspergillus niger, Alternaria alternata and Rhizopus oryzae than the use of films, where presumably, the chitosan solution had positive charges on the quaternary amino groups that interacted with the fungal cell walls, while for the films a protonation loss occurred.

The inhibitory effect of Ps was demonstrated on most of the pathogens tested ( $F$ circinatum, $D$. pinea, C. pararisitica, P. cambivora, $P$. $\times$ alni and $P$. plurivora). The use of propolis has not been as well studied as chitosan, although its inhibition capacity against $F$. circinatum was already reported by Iturritxa et al. (2013). However, they reported a fungicidal effect, whereas in this study a growth inhibition effect was found.

The application of AgNPs by itself also reduced the mycelial growth of $F$. circinatum and $D$. pinea, which is consistent with the results reported by Narayanan and Park (2014), who observed slight to moderate inhibition against wood-degrading fungi when a low dose of AgNPs was used. Nevertheless, AgNPs had not a significant anti-oomycete activity on the species tested in this study, contrasting with Mahdizadeh et al. (2015), who found that another oomycete (Pythium aphanidermatum (Edson) Fitzp.) was the most sensitive pathogen to nanosilver among the six tested species.

The effect of the binary solutions of the compound tested varies according to the species. While the COs-Ps binary solution showed the highest antifungal effect against $F$. circinatum, the result of the application of AgNPs in the binary solutions varies according to the pathogen. Indeed, the binary solution COs-AgNPs recommended by Wang et al. (2015) was the most promising mixture in order to control D, pinea. Nevertheless, the use of COs-AgNPs and Ps-AgNPs solutions had a counterproductive effect on the anti-fungal/oomycete activity against $G$. abietina and $P$. cambivora, respectively. This is in contrast to other studies in which nanosilver was also incorporated into chitosan, although in higher doses. For example against ascomycete Colletotrichum gloeosporioides (Penz.) Penz. \& Sacc., the mixture showed excellent results: the inhibitory action increased from $44 \%$ 312 2014). It is also noteworthy that the solution consisting only of AgNPs did not show statistically 313 significant difference $v s$. the control treatment, in contrast to the study by Narayanan and Park (2014), 
314 who observed slight to moderate inhibition against wood-degrading fungi when a low dose of AgNPs

315 was used. In the same vein, Saharan et al. (2013) and Saharan et al. (2015) found that the nanocopper-

316 chitosan complex showed growth inhibition against other ascomycota such as Fusarium oxysporum

317 and A. alternata. They suggested that addition of nanometals increased the surface charge density and

318 provided more electrostatic interaction with fungal membrane.

319 Differences in the inhibitory behavior of the similar COs-Ps-AgNPs mixture have been reported 320 for other fungal species and different application procedures: the COs-Ps-AgNPs ternary complex did 321 not improve the antifungal/anti-oomycete activity compared to the binary solutions in this study, 322 which contrasts with the complete inhibition obtained using similar COs-Ps-AgNPs mixtures applied 323 to D. seriata and Bipolaris oryzae (Breda de Haan) Shoemaker (Matei et al. 2015; Araujo-Rufino et 324 al. 2016). This discrepancy may be associated to that the gel phase used was ascribed to the higher 325 concentrations of chitosan oligomers in the gel $(20-25 \mathrm{mg} / \mathrm{mL}) v s$. the aqueous solution of this study $326(1 \mathrm{mg} / \mathrm{mL})$.

327 The bands in the ATR-FTIR spectrum of the COs-Ps-AgNPs composite evidenced a weak 328 interaction among COs and AgNPs, even weaker than that reported for chitosan-AgNPs thin films 329 and nanocomposites manufactured by spin-coating (Wei et al. 2009; Wang et al. 2015), whose 330 infrared spectra showed shifts between 5 and $10 \mathrm{~cm}^{-1}$. On the other hand, the spectrums of COs and 331 COs-Ps showed very similar bands to those reported in other works for chitosan (Matei et al. 2015; 332 Stroescu et al. 2015; Branca et al. 2016) and propolis extracts (Franca et al. (2014); Siripatrawan and 333 Vitchayakitti (2016).

334 A differential feature of this investigation in comparison to the literature was that in the 335 preparations described above Green Chemistry procedures were used, without need for the addition of chemical bond reinforcing agents, widely used in other works (Gu et al. 2014; Jemec et al. 2016). Accordingly, these eco-friendly compounds could be useful in management strategies based on integrated approach, for example in the use of appropriate nursery hygiene practices. Likewise, the application of chitosan had been suggested using the chitosan-based Biochikol 020 PC, a biological

341 forest nurseries (Oskazo 2007).

342 In conclusion, from the results of the in vitro growth inhibition experiments respect the anti343 fungal/oomycete effect of individual, binary and ternary mixtures of COs, Ps and AgNPs, assayed 344 against eight plant pathogens, it could be inferred that: $(i)$ the inhibitory activity against fungi and 345 oomycetes of the individual low molecular weight COs solutions was significantly high (reaching 346 growth rate reductions of up to $78,86,93 \%$ and $100 \%$ against G. abietina, C. parasitica, H. annosum 
and $P$. cambivora, respectively); (ii) the growth inhibition is enhanced by association of COs with Ps

348 (e.g., F. circinatum) and COs with AgNPs (e.g. D. pinea); and (iii) the COs-P-AgNPs ternary complex

349 did not improve the antifungal/anti-oomycete activity compared to the binary solutions. Thus, the

350 weak interactions that appear in solution amongst the three components (evidenced by FTIR)

351 suggested that strong interactions are necessary to achieve the desired anti-fungal/oomycete effect.

352 Additionally, further studies are essential to determine the effect of the COs-Ps-AgNPs combinations

353 on seeds, tree seedlings and mature trees infested by different pathogens, as an innovative application

354 system useful in an integrated management approach.

355

356

357

358

359

360

361

362

363

364

365

366

367

368

369

370

371

372

373

374

375

376

377

378

379

380

\section{Acknowledgments}

This article is based upon work from COST Action FP1406 PINESTRENGTH (Pine pitch canker - strategies for management of Gibberella circinata in greenhouses and forests), supported by COST (European Cooperation in Science and Technology) and project AGL2015-69370-R (MINECO/FEDER) funded by the Spanish Ministerio de Economía y Competitividad and the Fondo Europeo de Desarrollo Regional (FEDER). Calabazanos Forest Health Center - Junta de Castilla y León (Villamuriel de Cerrato, Palencia, Spain) is gratefully acknowledged for supplying the Cryphonectria parasitica, Heterobasidion annosum fungi and the Phytophthora cambivora oomycete. I. Silva Castro would like to gratefully acknowledge the financial support of CONACYT, México, through the PhD Scholarship with ref. no. 329975.

\section{Compliance with Ethical Standards}

The authors declare that they have no conflict of interest.

\section{References}

Adamson, K., Klavina, D., Drenkhan, R., Gaitnieks, T., \& Hanso, M. (2015). Diplodia sapinea is colonizing the native Scots pine (Pinus sylvestris) in the northern Baltics. European Journal of Plant Pathology, 143(2), 343-350, doi:10.1007/s10658-015-0686-8.

Araujo-Rufino, C., Fernandes-Vieira, J., Martín-Ramos, P., Silva-Castro, I., Fernandes-Correa, M., Matei, P. M., et al. (2016). Synthesis of chitosan oligomers composite systems and study of their activity against Bipolaris Oryzae. Journal of Materials Science and Engineering with Advanced Technology, 13(1), 29-52, doi:10.18642/jmseat_7100121578. 
Asiegbu, F. O., Adomas, A., \& Stenlid, J. A. N. (2005). Conifer root and butt rot caused by Heterobasidion annosum (Fr.) Bref. s.1. Molecular Plant Pathology, 6(4), 395-409, doi:10.1111/j.1364-3703.2005.00295.x.

Avelelas, F. P., Pinto, L. F., Velez, C., Azinheiro, S., Rodrigues, A., \& Leandro, S. M. (2014). Antifungal activity of low molecular weight chitosan produced from non-traditional marine resources. Frontiers in Marine Science, 1, doi:10.3389/conf.FMARS.2014.02.00048.

Boonlertnirun, S., Boonraung, C., \& Suvanasara, R. (2008). Application of chitosan in rice production. Journal of metals, materials and minerals, 18(2), 47-52.

Botella, L., Tuomivirta, T. T., Kaitera, J., Carrasco Navarro, V., Diez, J. J., \& Hantula, J. (2010). Spanish population of Gremmeniella abietina is genetically unique but related to type A in Europe. Fungal Biology, 114(9), 778-789, doi:10.1016/j.funbio.2010.07.003.

Branca, C., D'Angelo, G., Crupi, C., Khouzami, K., Rifici, S., Ruello, G., et al. (2016). Role of the $\mathrm{OH}$ and $\mathrm{NH}$ vibrational groups in polysaccharide-nanocomposite interactions: A FTIR-ATR study on chitosan and chitosan/clay films. Polymer, 99, 614-622, doi:10.1016/j.polymer.2016.07.086.

Chowdappa, P., Gowda, S., Chethana, C. S., \& Madhura, S. (2014). Antifungal activity of chitosansilver nanoparticle composite against Colletotrichum gloeosporioides associated with mango anthracnose. African Journal of Microbiology Research, 8(17), 1803-1812, doi:10.5897/ajmr2013.6584.

Cobos, R., Mateos, R. M., Álvarez-Pérez, J. M., Olego, M. A., Sevillano, S., González-García, S., et al. (2015). Effectiveness of natural antifungal compounds in controlling infection by grapevine trunk disease pathogens through pruning wounds. Applied and Environmental Microbiology, 81(18), 6474-6483, doi:10.1128/aem.01818-15.

El Hadrami, A., Adam, L. R., El Hadrami, I., \& Daayf, F. (2010). Chitosan in Plant Protection. Marine Drugs, 8(4), 968-987, doi:10.3390/md8040968.

Farooqui, T. (2012). Beneficial effects of propolis on human health and neurological diseases. Frontiers in Bioscience, E4(1), 779, doi:10.2741/e418.

Fitza, K. N. E., Payn, K. G., Steenkamp, E. T., Myburg, A. A., \& Naidoo, S. (2013). Chitosan application improves resistance to Fusarium circinatum in Pinus patula. South African Journal of Botany, 85, 70-78, doi:10.1016/j.sajb.2012.12.006.

Franca, J. R., De Luca, M. P., Ribeiro, T. G., Castilho, R. O., Moreira, A. N., Santos, V. R., et al. (2014). Propolis-based chitosan varnish: drug delivery, controlled release and antimicrobial activity against oral pathogen bacteria. BMC Complementary and Alternative Medicine, 14(1), doi:10.1186/1472-6882-14-478. 
Garbelotto, M., \& Gonthier, P. (2013). Biology, Epidemiology, and Control of Heterobasidion Species Worldwide. Annual Review of Phytopathology, 51(1), 39-59, doi:10.1146/annurevphyto-082712-102225.

García Pérez, A. (2011). Técnicas actuales de estadística aplicada. http://www2.uned.es/mastertecnicas-estadisticas/Material/GuiaM.pdf.

Gibson, I. A. S. (1979). Diseases of forest trees widely planted as exotics in the tropics and southern hemisphere. Part II. The genus Pinus. Kew, UK; Commonwealth Mycological Institute; Oxford: Commonwealth Forestry Institute.

González-Varela, G., González, A. J., \& Milgroom, M. G. (2011). Clonal population structure and introductions of the chestnut blight fungus, Cryphonectria parasitica, in Asturias, northern Spain. European Journal of Plant Pathology, 131(1), 67-79, doi:10.1007/s10658-011-97880 .

Gordon, T. R., Swett, C. L., \& Wingfield, M. J. (2015). Management of Fusarium diseases affecting conifers. Crop Protection, 73, 28-39, doi:10.1016/j.cropro.2015.02.018.

Gu, C., Zhang, H., \& Lang, M. (2014). Preparation of mono-dispersed silver nanoparticles assisted by chitosan-g-poly(E-caprolactone) micelles and their antimicrobial application. Applied Surface Science, 301(0), 273-279, doi:http://dx.doi.org/10.1016/j.apsusc.2014.02.059.

Haque, M. M., Martínez-Álvarez, P., Lomba, J. M., Martín-García, J., \& Diez, J. J. (2014). First report of Phytophthora plurivora causing collar rot on common alder in Spain. Plant Disease, 98(3), 425-425, doi:10.1094/pdis-07-13-0784-pdn.

Haque, M. M. U., Hidalgo, E., Martín-García, J., De-Lucas, A. I., \& Diez, J. J. (2015). Morphological, physiological and molecular characterization of Phytophthora alni isolates from Western Spain. European Journal of Plant Pathology, 142(4), 731-745, doi:10.1007/s10658-0150647-2.

Heiniger, U., \& Rigling, D. (1994). Biological control of chestnut blight in Europe. Annual Review of Phytopathology, 32(1), 581-599, doi:10.1146/annurev.py.32.090194.003053.

Hirooka, T., \& Ishii, H. (2013). Chemical control of plant diseases. Journal of General Plant Pathology, 79(6), 390-401, doi:10.1007/s10327-013-0470-6.

Husson, C., Aguayo, J., Revellin, C., Frey, P., Ioos, R., \& Marçais, B. (2015). Evidence for homoploid speciation in Phytophthora alni supports taxonomic reclassification in this species complex. Fungal Genetics and Biology, 77, 12-21, doi:10.1016/j.fgb.2015.02.013.

Iturritxa, E., Mesanza, N., \& Aitken, J. (2013). Bioensayos de control biológico y químico frente a Fusarium circinatum en Pinus radiata. In VI Congreso Forestal Español, Vitoria-Gasteiz, Spain, June 10-14, 2013 (pp. 1-8): Sociedad Española de Ciencias Forestales 
Jayakumar, R., Prabaharan, M., \& Muzzarelli, R. A. A. (2011). Chitosan for biomaterials (Advances in polymer science,, Vol. 243-244). Heidelberg; New York: Springer.

Jemec, A., Kahru, A., Potthoff, A., Drobne, D., Heinlaan, M., Böhme, S., et al. (2016). An interlaboratory comparison of nanosilver characterisation and hazard identification: Harmonising techniques for high quality data. Environment International, 87, 20-32, doi:10.1016/j.envint.2015.10.014.

Jönsson-Belyazio, U., \& Rosengren, U. (2006). Can Phytophthora quercina have a negative impact on mature pedunculate oaks under field conditions? Annals of Forest Science, 63(7), 661672, doi:10.1051/forest:2006047.

Jung, T., Hudler, G. W., Jensen-Tracy, S. L., Griffiths, H. M., Fleischmann, F., \& Osswald, W. (2005). Involvement of Phytophthora species in the decline of European beech in Europe and the USA. Mycologist, 19(4), 159-166, doi:10.1017/S0269915X05004052.

Jung, T., \& Burgess, T. I. (2009). Re-evaluation of Phytophthora citricola isolates from multiple woody hosts in Europe and North America reveals a new species, Phytophthora plurivora sp. nov. Persoonia - Molecular Phylogeny and Evolution of Fungi, 22(1), 95-110, doi:10.3767/003158509x442612.

Kaitera, J., \& Jalkanen, R. (1992). Disease history of Gremmeniella abietina in a Pinus sylvestris stand. Forest Pathology, 22(6-7), 371-378, doi:10.1111/j.1439-0329.1992.tb00309.x.

Kashyap, P. L., Kumar, S., Srivastava, A. K., \& Sharma, A. K. (2012). Myconanotechnology in agriculture: a perspective. World Journal of Microbiology and Biotechnology, 29(2), 191207, doi:10.1007/s11274-012-1171-6.

Kurzawińska, H., \& Mazur, S. (2006). The effect of Pythium oligandrum and chitosan used in control of potato against late blight and the occurrence of fungal diseases on tuber peel. Communications in Agricultural and Applied Biological Sciences, 72(4), 967-971.

Laflamme, P., Benhamou, N., Bussières, G., \& Dessureault, M. (2000). Differential effect of chitosan on root rot fungal pathogens in forest nurseries. Canadian Journal of Botany, 77(10), 14601468, doi:10.1139/b99-111.

Mahdizadeh, V., Safaie, N., \& Khelghatibana, F. (2015). Evaluation of antifungal activity of silver nanoparticles against some phytopathogenic fungi and Trichoderma harzianum. Journal of Crop Protection, 4(3), 291-300.

Marcucci, M. C. (1995). Propolis: chemical composition, biological properties and therapeutic activity. Apidologie, 26(2), 83-99, doi:10.1051/apido:19950202. 
Mărghitaş, L. A., Dezmirean, D. S., \& Bobiş, O. (2013). Important developments in Romanian propolis research. Evidence-Based Complementary and Alternative Medicine, 2013, 1-9, doi:10.1155/2013/159392.

Martínez-Álvarez, P., Alves-Santos, F., \& Diez, J. (2012). In vitro and in vivo interactions between Trichoderma viride and Fusarium circinatum. Silva Fennica, 46(3), doi:10.14214/sf.42.

Martínez-Álvarez, P., Fernández-González, R. A., Sanz-Ros, A. V., Pando, V., \& Diez, J. J. (2016). Two fungal endophytes reduce the severity of pitch canker disease in Pinus radiata seedlings. Biological Control, 94, 1-10, doi:10.1016/j.biocontrol.2015.11.011.

Matei, P. M., Martin-Ramos, P., Sanchez-Bascones, M., Hernandez-Navarro, S., Correa-Guimaraes, A., Navas-Gracia, L. M., et al. (2015). Synthesis of Chitosan Oligomers/Propolis/Silver Nanoparticles Composite Systems and Study of Their Activity against Diplodia seriata. International Journal of Polymer Science, 2015, 1-11, doi:10.1155/2015/864729.

Narayanan, K. B., \& Park, H. H. (2014). Antifungal activity of silver nanoparticles synthesized using turnip leaf extract (Brassica rapa L.) against wood rotting pathogens. European Journal of Plant Pathology, 140(2), 185-192, doi:10.1007/s10658-014-0399-4.

Ngo, D.-H., Vo, T.-S., Ngo, D.-N., Kang, K.-H., Je, J.-Y., Pham, H. N.-D., et al. (2015). Biological effects of chitosan and its derivatives. Food Hydrocolloids, 51, 200-216, doi:10.1016/j.foodhyd.2015.05.023.

Olicón-Hernández, D. R., Hernández-Lauzardo, A. N., Pardo, J. P., Peña, A., Velázquez-del Valle, M. G., \& Guerra-Sánchez, G. (2015). Influence of chitosan and its derivatives on cell development and physiology of Ustilago maydis. International Journal of Biological Macromolecules, 79, 654-660, doi:10.1016/j.ijbiomac.2015.05.057.

Oskazo, T. (2007). Alder decline in Poland. Communicationes Instituti Forestalis Bohemicae, Vulhm, $23,125-137$.

Özcan, M., Ünver, A., Ceylan, D. A., \& Yetisir, R. (2004). Inhibitory effect of pollen and propolis extracts. Nahrung/Food, 48(3), 188-194, doi:10.1002/food.200300296.

Qiu, M., Wu, C., Ren, G., Liang, X., Wang, X., \& Huang, J. (2014). Effect of chitosan and its derivatives as antifungal and preservative agents on postharvest green asparagus. Food Chemistry, 155, 105-111, doi:10.1016/j.foodchem.2014.01.026.

R Development Core Team (2016). R: A language and environment for statistical computing. (3.3.1 ed.). Vienna, Austria: R Foundation for Statistical Computing.

Reglinski, T., Taylor, J. T., \& Dick, M. A. (2004). Chitosan induces resistance to pitch canker in Pinus radiata. New Zealand Journal of Forestry Science, 34(1), 49-58. 
Romeralo, C., Witzell, J., Romeralo-Tapia, R., Botella, L., \& Diez, J. J. (2015). Antagonistic activity of fungal endophyte filtrates against Gremmeniella abietina infections on Aleppo pine seedlings. European Journal of Plant Pathology, 143(4), 691-704, doi:10.1007/s10658-0150719-3.

Saharan, V., Mehrotra, A., Khatik, R., Rawal, P., Sharma, S. S., \& Pal, A. (2013). Synthesis of chitosan based nanoparticles and their in vitro evaluation against phytopathogenic fungi. International Journal of Biological Macromolecules, 62, 677-683, doi:10.1016/j.ijbiomac.2013.10.012.

Saharan, V., Sharma, G., Yadav, M., Choudhary, M. K., Sharma, S. S., Pal, A., et al. (2015). Synthesis and in vitro antifungal efficacy of $\mathrm{Cu}$-chitosan nanoparticles against pathogenic fungi of tomato. International Journal of Biological Macromolecules, 75, 346-353, doi:10.1016/j.ijbiomac.2015.01.027.

Singh, T., Vesentini, D., Singh, A. P., \& Daniel, G. (2008). Effect of chitosan on physiological, morphological, and ultrastructural characteristics of wood-degrading fungi. International Biodeterioration \& Biodegradation, 62(2), 116-124, doi:10.1016/j.ibiod.2007.09.006.

Siripatrawan, U., \& Vitchayakitti, W. (2016). Improving functional properties of chitosan films as active food packaging by incorporating with propolis. Food Hydrocolloids, 61, 695-702, doi:10.1016/j.foodhyd.2016.06.001.

Stroescu, M., Stoica-Guzun, A., Isopencu, G., Jinga, S. I., Parvulescu, O., Dobre, T., et al. (2015). Chitosan-vanillin composites with antimicrobial properties. Food Hydrocolloids, 48, 62-71, doi:10.1016/j.foodhyd.2015.02.008.

Torlak, E., \& Sert, D. (2013). Antibacterial effectiveness of chitosan-propolis coated polypropylene films against foodborne pathogens. International Journal of Biological Macromolecules, 60, 52-55, doi:10.1016/j.ijbiomac.2013.05.013.

Venkatesham, M., Ayodhya, D., Madhusudhan, A., Veera Babu, N., \& Veerabhadram, G. (2012). A novel green one-step synthesis of silver nanoparticles using chitosan: catalytic activity and antimicrobial studies. Applied Nanoscience, 4(1), 113-119, doi:10.1007/s13204-012-0180-y.

Wang, L.-S., Wang, C.-Y., Yang, C.-H., Hsieh, C.-L., Chen, S.-Y., Shen, C.-Y., et al. (2015). Synthesis and anti-fungal effect of silver nanoparticles-chitosan composite particles. International Journal of Nanomedicine, 2685, doi:10.2147/ijn.s77410.

Wang, W.-q., Zhang, P., Meng, R.-j., Zhao, J.-j., Huang, Q.-1., Han, X.-y., et al. (2014). Fungitoxicity and synergism of mixtures of fluopicolide and pyraclostrobin against Phytophthora infestans. Crop Protection, 57, 48-56, doi:10.1016/j.cropro.2013.11.027. 
Wei, D., Sun, W., Qian, W., Ye, Y., \& Ma, X. (2009). The synthesis of chitosan-based silver nanoparticles and their antibacterial activity. Carbohydrate Research, 344(17), 2375-2382, doi:10.1016/j.carres.2009.09.001.

Wilcox, R. R. (2016). Introduction to robust estimation and hypothesis testing (4th edition. ed.). Waltham, MA: Elsevier.

Wingfield, M. J., Hammerbacher, A., Ganley, R. J., Steenkamp, E. T., Gordon, T. R., Wingfield, B. D., et al. (2008). Pitch canker caused by Fusarium circinatum - a growing threat to pine plantations and forests worldwide. Australasian Plant Pathology, 37(4), 319, doi:10.1071/ap08036.

Yoksan, R., \& Chirachanchai, S. (2010). Silver nanoparticle-loaded chitosan-starch based films: Fabrication and evaluation of tensile, barrier and antimicrobial properties. Materials Science and Engineering: C, 30(6), 891-897, doi:10.1016/j.msec.2010.04.004.

Zamora, P., Martín, A. B., Rigling, D., Diez, J. J., \& Woodward, S. (2012). Diversity of Cryphonectria parasitica in western Spain and identification of hypovirus-infected isolates. Forest Pathology, 42(5), 412-419, doi:10.1111/j.1439-0329.2012.00775.x.

Zamora-Ballesteros, C., Haque, M. M. U., Diez, J. J., Martín-García, J., \& Balci, Y. (2016). Pathogenicity of Phytophthora alni complex and P. plurivora in Alnus glutinosa seedlings. Forest Pathology, doi:10.1111/efp.12299.

Zeng, D., Luo, X., \& Tu, R. (2012). Application of bioactive coatings based on chitosan for soybean seed protection. International Journal of Carbohydrate Chemistry, 2012, 1-5, doi:10.1155/2012/104565.

Ziani, K., Fernández-Pan, I., Royo, M., \& Maté, J. I. (2009). Antifungal activity of films and solutions based on chitosan against typical seed fungi. Food Hydrocolloids, 23(8), 2309-2314, doi:10.1016/j.foodhyd.2009.06.005. 